\title{
La perspectiva hermenéutica y el sentido de la comunicación en el contexto de la sociocultura*
}

\author{
José Alfredo Villarreal Valera** \\ Yovanis Rosales Almarales*** \\ Alex Rodrigo Rivera Ríos ${ }^{* \star * *}$ \\ Recibido: 2017-11-15 Enviado a pares: 2017-11-25 \\ Aprobado por pares: 2018-01-16 - Aceptado: 2018-03-03 \\ DOI: 10.22395/angr.v16n32a5
}

\begin{abstract}
Resumen
El presente artículo tiene como objetivo definir la importancia de la hermenéutica como herramienta metodológica para entender el proceso de la comunicación. Para ello se siguió una estrategia investigativa que privilegia la revisión analítica de fuentes originales, así como el empleo de métodos teóricos y empíricos, tales como la observación, las entrevistas y la triangulación teórica, por medio de la combinación de paradigmas cuantitativos y cualitativos. El mismo ofrece como resultado novedoso una sistematización que, desde una perspectiva interpretativa, explica el papel indispensable de la hermenéutica para comprender los significados de las prácticas de comunicación, desde cuyo enfoque esta no ha sido suficientemente tratada.
\end{abstract}

Palabras clave: comprensión; comunicación; explicación; hermenéutica; interpretación.

\footnotetext{
Este trabajo es un artículo resultado del proyecto de investigación interdisciplinar doctoral titulado Interacción prácticas culturales-prácticas de comunicación entre los sujetos, desde la dimensión sociocultural, en cuya estructura se analiza e interpreta la perspectiva metodológica hermenéutica y su validez en el proceso de la comunicación, para lo que se recurre a fuentes originales; desarrollado por el autor principal desde la Facultad de Estudios Socioculturales de la Universidad de Granma (Cuba), con la tutoría de ambos coautores y financiado por la misma Universidad.

** Doctor en Ciencias Sociológicas. Profesor titular de la Universidad de Granma (Cuba). jvillarrealv@udg.co.cu

*** Máster en Estudios Sociales y de la Comunicación. Profesor auxiliar de la Universidad de Granma (Cuba).yrosalesa@ udg.co.cu

...* Doctor en Química Industrial. Magíster en Docencia Universitaria e Investigación Educativa. Docente de la Universidad Técnica de Machala (Ecuador). arrivera@utmachala.edu.ec
} 


\title{
The Hermeneutic Perspective and the Sense of Communication in the Context of Socioculture
}

\begin{abstract}
The objective of this article is to define the importance of hermeneutics as a methodological tool to understand the communication process. To this end, a research strategy that privileges the analytical review of original sources was used, as well as theoretical and empirical methods such as observation, interviews and theoretical triangulation, through the combination of quantitative and qualitative paradigms. As a novel result, the study presents a systematization that, from an interpretive perspective, explains the indispensable role of hermeneutics for understanding the meanings of communication practices, given that it has not been sufficiently addressed by their focus.
\end{abstract}

Keywords: Comprehension; communication; explanation; hermeneutics; interpretation.

\section{A perspectiva hermenêutica e o sentido da comunicação no contexto da sociocultura}

\begin{abstract}
Resumo
Este artigo tem como objetivo definir a importância da hermenêutica como ferramenta metodológica para entender o processo da comunicação. Para isso, seguiu-se uma estratégia de pesquisa que privilegia a revisão analítica de fontes originais bem como o emprego de métodos teóricos e empíricos, tais como a observação, as entrevistas e a triangulação teórica, por meio da combinação de paradigmas quantitativos e qualitativos. Isso oferece como resultado uma sistematização que, sob a perspectiva interpretativa, explica o papel indispensável da hermenêutica para compreender os significados das práticas de comunicação; a abordagem da hermenêutica não tem sido suficientemente tratada na literatura.
\end{abstract}

Palavras-chave: compreensão; comunicação; explicação; hermenêutica; interpretação. 


\section{Introducción}

La comunicación ha sido definida por diversos autores desde las más variadas perspectivas. A los efectos de este artículo se comprende como un proceso social que se sustenta en la interrelación dialógica entre personas; es un proceso mediado, interactivo, situado y local, presente en todas las esferas de la actividad del ser humano en una interacción directamente proporcional entre los sujetos. Es concebida como proceso sociológico multirrelacional, como el acto de compartir, construir un diálogo cultural entre sujetos que están instituidos en un lugar social, propiedad humana y componente consustancial de las relaciones sociales, dada la esencia socio-histórica del hombre. Ella solo existe como resultado de la actividad de los sujetos sociales y de las relaciones derivadas de la misma; de ahí que a la hermenéutica, definida en este artículo como ciencia o método universal cuya finalidad es la interpretación y la comprensión, léase el entendimiento crítico y objetivo del sentido de las cosas en su generalidad, corresponda la función de hacer comprensibles los símbolos que intervienen en la comunicación.

Esto significa que en el proceso comunicacional es necesario poseer la capacidad de reconstruir hermenéuticamente textos sociales a partir de códigos y símbolos que se mueven bajo determinadas condicionantes socioculturales y que constituyen redes de significación. Esta reconstrucción requiere la "explicación, interpretación y comprensión de dichos textos sociales concebidos relacionalmente" (Abellán, 2007, p. 24).

Por tanto, la problemática a dilucidar en este artículo gira en torno a la interrogante: ¿cómo se reconstruirían hermenéuticamente los textos (símbolos, signos, significados) de la comunicación y a partir de qué contextos socioculturales?

En busca de explicación de la misma, nos proponemos como objetivo definir la importancia de la hermenéutica como herramienta metodológica para entender el proceso de la comunicación.

\section{Estrategia metodológica}

La estrategia metodológica seguida para la investigación parte de la selección, revisión y análisis crítico de fuentes bibliográficas, provenientes en su mayoría del campo de la comunicación y de la sociología, incluyendo textos escritos por hermeneutas clásicos. Para ello se tuvieron en cuenta los postulados de numerosos representantes de algunas de las principales escuelas de pensamiento en el campo de la comunicación, la hermenéutica y la sociología cultural; tales son los casos, entre otros, de Jürgen Habermas, quien revaloriza el papel de la hermenéutica como método en las ciencias sociales y humanas, asociándola al análisis de los sistemas sociales; Paul Ricoeur, el cual considera que, de un lado, no hay reflexión sin meditación sobre los signos; de otro, no hay explicación sin la comprensión del mundo y de sí mismo, y Martin Heidegger que afirma que la comprensión, cualquiera que sea, presenta una estructura circular.

El desarrollo metodológico se fundamenta en la triangulación teórica y metodológica e integra diversos métodos y técnicas de investigación, desde la investigación documen- 
tal y el diálogo de saberes, hasta el método analítico sintético, inductivo deductivo, la observación, la práctica de las redes conversacionales y la aplicación de cuestionarios, entrevistas grupales y consultas a expertos.

\section{Hermenéutica y comunicación en la sociocultura}

El concepto de hermenéutica "proviene de la expresión griega hermeneúcin, que significa el arte de interpretar, en su sentido más amplio" (Gutiérrez, 1986). La idea de la hermenéutica es la sustentación de una ciencia o método universal cuya finalidad es la interpretación y la comprensión, léase el entendimiento crítico y objetivo del sentido de las cosas en su generalidad. "Esto significa que la hermenéutica intenta establecer un proceso por medio del cual se haga, inicialmente, una interpretación en torno al sentido de cualquier fenómeno, y en una segunda instancia, se realice la comprensión del mismo" (Gutiérrez, 1986, p. 155).

Si observamos la complejidad del entramado social, podemos percibir que "comunicación, cultura, sociedad se condicionan, se presuponen, en tanto la comunicación es un proceso y resultado social" (Espronceda, 2009, p. 10) y "la sociedad es un hecho profundamente cultural" (Williams,1981, p. 20), o sea, los vínculos existentes entre comunicación y cultura se expresan mediante un adecuado proceso de percepción, interpretación y comprensión de la multiplicidad simbólica que interviene durante las relaciones socioculturales que se establecen entre los diferentes actores sociales.

Ahí adquieren su peso y su relieve -en la trama cultural heterogénea, en la diversidad de formas y de prácticas, de estilos de vivir, de estructuras del sentir, de modos de narrar- las actuales imbricaciones entre cultura y comunicación, su remitir no solo a los efectos de los medios y sus innovaciones tecnológicas, sino a las nuevas formas de sociabilidad con las que la gente enfrenta la heterogeneidad simbólica (Barbero, 1995, pp. 35).

Visto de esta manera, a la cultura corresponde el papel mediador en la práctica comunicacional. De acuerdo con Jesús Martín Barbero, la mediación es el lugar desde donde se conforman los sentidos que dan los sujetos a sus prácticas sociales, por tanto, desde donde se otorga sentido al proceso de comunicación; la gran mediadora de todo proceso de producción comunicativa es la cultura.

Tales prácticas tienen lugar en la estructura ideacional que en el nivel individual y colectivo se incorpora con los conocimientos, las creencias, los sentimientos y modos de ver y disfrutar la vida, por lo que es indispensable que se identifique no solo el pasado histórico, social y cultural, que ha estructurado a cada interlocutor, sino, también, el presente social del que forma parte y la manera como su actuación es resultado de lo aprendido, y la forma en que los sigue es el resultado de cómo habrán de percibir la vida, el mundo y la sociedad.

De aquí que en el proceso de comunicación concurran múltiples mediaciones culturales, situacionales, económicas, familiares, las cuales inciden en la interacción comu- 
nicativa y constituyen las mediaciones que posibilitan o dificultan la comunicación entre los interlocutores.

Esta conceptualización, acuñada por Barbero, permite superar la postura centrada en los medios artefactuales que transportan información, monopolizan y anarquizan los procesos de comunicación, por una nueva interdisciplinariedad de los espacios estratégicos dados por la sociología de la cultura, los estudios de la comunicación, la nueva antropología, la politología cultural, etc. De este modo, los medios son parte de las mediaciones sociales existentes, que apuntan a los procesos de interacción y reconstrucción cultural.

Pero dicho proceso requiere del papel metodológico de la hermenéutica como herramienta que da cabida a la significación sociocultural contenida en lo que se comunica. La misión de la hermenéutica como método aplicable al proceso de la comunicación es descubrir los significados, interpretar lo mejor posible las palabras, los escritos, los textos y los gestos, los movimientos, las explicaciones, las expresiones, las formas no verbales de comunicación, los sistemas y códigos culturales, así como cualquier acto u obra que pueda tener algún significado, pero conservando su singularidad en el contexto del que forma parte.

Para asumir la hermenéutica como herramienta de la comunicación, se precisa comprender que la primera posibilita la formación o el desarrollo de determinadas habilidades en el proceso de la segunda, siempre que se privilegie la concepción acerca de que el mismo solo es posible en un "espacio de interacción social, atravesado por la capacidad de observar, explicar, interpretar y comprender el contexto sociocultural" (Rizo, 2006, p. 20).

Lo anterior significa que los sujetos interactuantes en la comunicación deben poseer una determinada competencia hermenéutica como herramienta, y estar en condiciones de conocer y aplicar el arte de interpretar textos sociales y contextos que les faciliten el camino hacia la comprensión de la situación o la realidad objeto de comunicación.

En este sentido, se entiende por textos sociales: el discurrir por medio de la actividad del discurso; cualquier forma cultural en la que se socializa un discurso; los códigos, que "se mueven como lenguaje y signos" (Hall, 1980, p.133), significados, manuscritos, símbolos, que motivan la acción del individuo. Por su parte, el contexto se refiere al "entramado o tejido de significados provenientes del medio ambiente o entorno, que impresionan el intelecto o campo de conocimientos de un grupo humano, como parte integrante de su cultura y su visión de mundo o cosmovisión" (Hall, 2004, p.20); es todo aquello que forma parte del medio ambiente o entorno y resulta significativo en la formación y desarrollo de un grupo humano específico; el entorno ambiental, social y humano que condiciona el hecho de la comunicación; el entorno más la significación cognitiva para el grupo social; es por ello que la palabra contexto es usada para referirse al medio ambiente, pero con un sentido comunicacional. Incluye el condicionamiento social. Para el funcionalismo es la estructura.

Creyendo con Max Weber que el hombre es un animal inserto en tramas de significación que él mismo ha tejido, considero que la cultura es esa urdimbre y 
que el análisis de la cultura ha de ser, por lo tanto, no una ciencia experimental en busca de leyes, sino una ciencia interpretativa en busca de significaciones. Lo que busco es la explicación, interpretando expresiones sociales que son enigmáticas en su superficie. Una vez que la conducta humana es vista como acción simbólica -acción que, lo mismo que la fonación en el habla, el color en la pintura, las líneas en la escritura o el sonido en la música, significa algopierde sentido la cuestión de saber si la cultura es conducta estructurada, o una estructura de la mente, o hasta las dos cosas juntas mezcladas. Aquello por lo que hay que preguntar es por su sentido y su valor. La cultura es pública porque la significación lo es. El análisis cultural es (o debería ser) conjeturar significaciones, estimar las conjeturas y llegar a conclusiones explicativas partiendo de las mejores conjeturas, y no el descubrimiento del continente de la significación y el mapeado de su paisaje incorpóreo. Como ya dije, todo el quid de un enfoque semiótico de la cultura es ayudarnos a lograr acceso al mundo conceptual en el cual viven nuestros sujetos, de suerte que podamos, en el sentido amplio del término, conversar con ellos (Geertz, 1992, p. 36).

Este enfoque es necesario en el ámbito de la sociocultura para poder explicar con rigor los procesos de

- Establecimiento de necesidades y significados comunicacionales en el interior del individuo que participa de una interacción comunicativa intersubjetiva.

- Interpretación de los códigos y símbolos contenidos en los mensajes del otro sujeto. Es importante en la comunicación considerar el contenido latente del mensaje, no solo el manifiesto, pues a veces pueden contraponerse.

- Autointerpretación.

El enfoque hermenéutico en el contexto de la sociocultura conduce a entender el proceso interpretativo que se lleva a cabo por los sujetos y lo acumulado por sus experiencias. Esta aproximación enriquece la comunicación. Es en este sentido que apreciamos el encuadre hermenéutico, comunicativo, sociocultural de la teoría de Jürge Habermas, pues este entiende por acción comunicativa la "forma de interacción social coordinada por el empleo del lenguaje orientado a entenderse que, por tanto, ha de constituir una forma de interacción en cierto modo supuesta en todas las demás" (Habermas, 1981, p. 54), y entiende el discurso como forma de reflexión de la acción comunicativa.

Habermas apuesta por las posibilidades de la razón humana, el valor de la conciencia social, afincadas en la posibilidad que ofrecen el diálogo y la acción comunicativa, revaloriza el papel de la hermenéutica, como método en las ciencias sociales y humanas. En el contexto de su pensamiento, la hermenéutica debe ir asociada al análisis de los sistemas sociales.

Es indispensable abrir el pensamiento para explicarnos el fenómeno de la subjetividad, es muy importante en el plano de las investigaciones antropológicas, culturales y de otras ciencias y disciplinas; "pero es apremiante su utilización en el ambiente cotidiano de la comunicación" (Goffman, 1972, p. 24). 
La perspectiva metodológica hermenéutica es la que abarca la complejidad de la interacción sujeto comunicante-sujeto comunicado, porque implica participar desde el interior de la interacción intersubjetiva, sin desconectar para conocer y sin reducirse para tomar decisiones conjuntas, a ninguno de los roles.

En aquellos modelos en los que la comunicación se basa únicamente en la relación sujeto-objeto, la misma tiene un carácter unidireccional, no procesal, que se queda, de un lado, en los marcos de la información o emisión de mensajes y, del otro, en la recepción pasiva, con ausencia de la dinámica participativa, mientras que en la perspectiva que estamos exponiendo, los sujetos forman parte intrínseca de la comunicación, ambos buscando información, esperando llegar a un consenso de su jerarquía de valores (previo conocimiento y respeto mutuos), para, de conjunto, explicar, interpretar y comprender para realizar acciones.

Como se puede apreciar, la comprensión ocupa el centro de la perspectiva hermenéutica de la comunicación, cuya estructura se puede considerar de la manera siguiente:

- Estructura de horizonte: el contenido singular y aprendido en la totalidad de un contexto de sentido, que es preaprendido y coaprendido.

- Estructura circular: la comprensión se mueve en una dialéctica entre la precomprensión y la comprensión de la cosa; es un acontecimiento que progresa en forma de espiral, en la medida que un elemento presupone otro y al mismo tiempo hace como que va adelante.

- Estructura de diálogo: en el diálogo mantenemos nuestra comprensión abierta, para enriquecerla y corregirla.

- Estructura de mediación: la mediación se presenta y se manifiesta en todos los contenidos, pero se interpreta como comprensión en nuestro mundo y en nuestra historia.

Esta circularidad hermenéutica, que de acuerdo con Martin Heidegger consiste en que toda interpretación, para producir comprensión, debe ya tener comprendido lo que va a interpretar, o sea, para comprender es necesario haber comprendido ya previamente, es decir, ha de existir una pre-comprensión anterior a toda comprensión, permite que el sujeto (yo) se ponga en el papel del sujeto (otro) y viceversa.

Esta última idea conduce al análisis de la relación que tienen los conceptos de alteridad u otredad y de representación social con el proceso de la comunicación.

El diálogo, la comunicación, sitúa al otro como un interlocutor, productor de una verdad que por momentos debe ser traducida. Es por esto que resulta recomendable establecer sistemas de interpretación entre los sujetos. Es en el intercambio verbal donde emergen los significados sociales. El éxito de la comunicación se derivará de la "capacidad y habilidad de ambas partes a la hora de preguntar, escuchar, empatizar e interactuar relacionalmente" (Donati, 1993, p. 20). 
De esta manera, la comunicación es una construcción simbólica que opera como forma de categorización de lo social, es comprender lo que somos mirándonos en el espejo del otro; por tanto, no podemos comprenderla sin tener en cuenta la alteridad, o sea, la interacción ocupa el centro de la comunicación. Hablar de los mundos simbólicos es hablar, como dice José Joaquín Brunner, de representaciones colectivas, creencias profundas, estilos cognitivos, comunicación de símbolos, juegos de lenguaje, sedimentación de tradiciones.

La construcción de la alteridad depende de las representaciones culturales que existan en el espacio social. Esto significa que "... la imagen del otro se consolida a partir de una representación mental, de un imaginario colectivo, mediante imágenes, ritos y múltiples dispositivos simbólicos, de manera que estos registros culturales no solo enuncien, sino que, a la vez, reafirmen las diferencias" (M. Nash, 2001:38).

El análisis de la perspectiva hermenéutica de la comunicación no puede dejar de considerar el papel que en este sentido corresponde a la representación social. Las representaciones se generan de manera colectiva, en términos de conceptos, ideas, categorías, sentimientos, emociones, móviles de actos y de prácticas tradicionales, etc.; por eso, "determinan casi todos los aspectos de la vida social, pues son, en todo caso, estructuras que fundan relaciones y comportamientos" (Vizer, 2003, p. 50).

La representación social de los sujetos acerca de la comunicación expresada en buena, regular o mala "es construida culturalmente con variaciones en el tiempo y el espacio" (Moscovici, 1986, p. 34). Esto quiere decir que para grupos sociales diferentes por sus patrones culturales, la comunicación tiene sentidos diferentes en dependencia del modo en que se logre hermenéuticamente la adecuada explicación, comprensión e interpretación para ese grupo. Cada uno de ellos construye sistemas y niveles distintos de comunicación.

\section{Conclusiones}

El papel de la hermenéutica como herramienta de la comunicación en la sociocultura es descubrir los significados de las cosas, interpretar lo mejor posible las palabras, los escritos, los textos y los gestos, los movimientos, las explicaciones, las expresiones, las historias de vida, el comportamiento en general, las formas no verbales de conducta, los sistemas culturales, las organizaciones sociales y los sistemas conceptuales científicos, religiosos o filosóficos, así como cualquier acto u obra que pueda tener algún significado, pero conservando su singularidad en el contexto del que forman parte.

La hermenéutica se constituye en una herramienta metodológica útil para la comunicación y el análisis en los procesos socioculturales, pues permite no solo explicar e interpretar, sino la comprensión de estructuras, de funcionamiento, descubrir los sistemas dinámicos que se dan en los seres humanos o en la organización y "dinámica de grupos de personas, étnicos o sociales y que explican el origen, las dimensiones, la construcción social, cultural, la multicausalidad y la evolución de los problemas observados" (LéviStrauss, 2005 p. 464 ). 


\section{Referencias}

Abellán, A. (2007). El pensamiento relacional como fundamento para una nueva teoría de la comunicación. Comunicación y Hombre, (3), 20-34.

Barbero, J. (1995). Mediaciones urbanas y nuevos escenarios de comunicación. Sociedad, (5), 35-47.

Donati, P. (1993). Pensamiento sociológico y cambio social: hacia una teoría relacional. REIS: Revista española de investigaciones sociológicas, 63, 10-40.

Espronceda, M. (2009). Pertinencias y alcances de la sociología cultural en el encuadre sociológico. Algunas notas Cultura y Comunicación. Revista Santiago, (119), 1-12.

Geertz, C. (1992). La interpretación de las culturas. Barcelona, España: Editorial Gedisa.

Goffman, I. (1972). La presentación de la persona en la vida cotidiana. Buenos Aires, Argentina: Amorrortu.

Gutiérrez, P. (1986). La hermenéutica como método. Metodología de las Ciencias Sociales, (2), 139-165.

Hall, S. (2004). Estudios culturales: Dos Paradigmas. Revista Colombiana de Sociología, 2(27), 233-254.

Habermas, J. (1981). Teoría de la acción comunicativa. Madrid, España: Editorial Taurus Humanidades.

Lévi-Strauss, C. (2005). Estructura social. En P. Bohanna y M. Glazer (Eds.), Lecturas Antropología (pp. 440-474). La Habana, Cuba: Editorial Félix Varela.

Martín, M. (2003). Teoría de la comunicación: una propuesta. Madrid, España: Tecnos.

Moscovici, S. (1986) Psicología social II. Pensamiento y vida social. Barcelona, España: Editorial Paidós Ibérica.

Nash, M. (2001). Multiculturalismo y género. Un estudio interdisciplinar. Barcelona, España: Ediciones Bellaterra.

Rizo, M. (2006). George Simmel, Sociabilidad e Interacción: aportes a la ciencia de la comunicación. Revistas Cinta de Moebio, (27), 43-60.

Vizer, E. (2003). La trama (in)visible de la vida social. Buenos Aires, Argentina: La Crujía Ediciones.

Williams, R. (1981). Cultura: sociología de la comunicación y del arte. Buenos Aires, Argentina: Editorial Paidós Ibérica. 